\title{
Management of refractory epilepsy by using polyunsaturated fatty acid ketogenic diet - A case study
}

\author{
Subhasree Ray, ${ }^{1, *}$, Meena Godhia² \\ ${ }^{1}$ Ph.D. Scholar, ${ }^{\mathbf{2}}$ Associate Professor, ${ }^{1}$ Dept. of Food Science and Nutrition, ${ }^{2}$ Dept. of Food, Nutrition and Dietetics ${ }^{1}$ SNDT \\ Women's University, Mumbai, Maharashtra, ${ }^{2}$ Sir Vithaldas Thackersey College of Home Science, SNDT Women's University, \\ SNDT Vidyavihar, Mumbai, Maharashtra, India \\ *Corresponding Author: \\ Email: roysubhoshree@gmail.com
}

\begin{abstract}
Ketogenic Diet (KD) is a high-fat, low carbohydrate and normal or high protein diet at a ratio of 4:1 (Fat: Carbohydrate+Protein), predominantly used in refractory epilepsy. The fat used in classical ketogenic diet are predominantly saturated fatty acids. PolyUnsaturated Fatty Acid Ketogenic Diet (PUFAKD) is composed of high polyunsaturated fatty acids (omega-6 and omega-3 at 2.8:1 ratio), optimum protein and low carbohydrate. A patient, after failure of 3 consecutive anti-epileptic drugs consulted the neurologist at an epilepsy management clinic and diagnosed as a case of refractory epilepsy. In the current case study, the patient (27 months old girl) was experiencing generalized tonic-clonic seizures. She was advised PUFAKD for 6 months to control the seizures and the progress was monitored during each monthly follow up. The PUFAKD intervention showed $50 \%, 65 \%$ and $80 \%$ seizure reduction at $3^{\text {rd }}$ month, $4^{\text {th }}$ month and $6^{\text {th }}$ month respectively. The Anti-epileptic drugs (AEDs) were reduced from 3 to 2 after 6 months of intervention. The patient has shown 100\% tolerability to the diet with no side effects. The present case study demonstrates promising role of PUFAKD in controlling refractory epilepsy.
\end{abstract}

Keywords: Ketogenic diet, Epilepsy, Seizure, Children, Dietary Management, Nutrition.

\section{Introduction}

Epilepsy is a prevalent and serious neurological disorders. As per International League Against Epilepsy (ILAE) task force, created in 2014, epilepsy is considered to be a disease of the brain defined by any of the following conditions ${ }^{1}$ :

1. At least two unprovoked (or reflex) seizures occurring $>24$ hour apart.

2. One unprovoked (or reflex) seizure and a probability of further seizures similar to the general recurrence risk (at least $60 \%$ ) after two unprovoked seizures occurring over the next 10 years.

According to ILAE, Drug resistant epilepsy may be defined as failure of adequate trials of two tolerated and appropriately chosen and used AED schedules (whether as monotherapies or in combination) to achieve sustained seizure freedom. ${ }^{2}$

Over decades of research it has been shown that the ketogenic diet is a safe and effective mode of alternative therapy for refractory epilepsy. ${ }^{3}$ In classical ketogenic diet, the ratio of the macronutrients in the diet is typically maintained at $4: 1$ (Fat:Carbohydrate+Protein) or 3:1 and the type of fat is not defined. Saturated fats are predominantly used in this diet regimen. ${ }^{4}$ In Poly-Unsaturated Fatty Acid Ketogenic Diet (PUFAKD) the type of fats used are specifically polyunsaturated in nature. Polyunsaturated fatty acids include omega-6 (n-6) and omega-3 (n-3) fatty acids, used in a ratio of 2.8:1 in PUFAKD. Taha $e t$ al (2014) has opined that DHA should be used in higher quantities (3-6 gm/day), for a longer period (3-6 months) and at a ratio of $n-6: n-3$ of $2.8: 1$ to reduce seizure frequency in refractory epilepsy. ${ }^{5}$
The following case study presents the use of PUFAKD in a paediatric patient who had refractory epilepsy and opted for ketogenic diet therapy.

\section{Material and Methods}

General Information: The patient was a full term, $3 \mathrm{~kg}$ 230 g gestational body weight, 27 months, old girl who has consulted the neurologist at an epilepsy management clinic in the year 2017. The patient had no history of genetic predisposition. On the $12^{\text {th }}$ day of life the patient had recurrent general tonic-clonic jerks, 1012 episodes per each lasting for 10-20 seconds. The patient was put on 3 anti-epileptic drugs (AEDs) for 65 days from the day of the seizure onset with poor or no response. Thus she had refractory epilepsy.

\section{Observation and Medication:}

a. Seizures Detail: The patient was experiencing general tonic-clonic seizure, $10-12$ per day, $10-20$ sec per seizure. 3 anti-epileptic drugs were introduced at a frequency of 2 tablets each with poor or no response.

b. EEG and MRI: Routine sleep electroencephalogram (EEG) and Magnetic Resonance Imaging (MRI) of the brain were performed at the time of admission. The EEG was reported as abnormal with generalized spike and wave discharges during sleep. Brain MRI was reported as normal.

c. Quantitative Biochemical Parameters: Routine blood and urine tests were conducted including total serum protein, albumin, globulin, albumin:globulin, sodium, potassium, chlorides, 
phosphorus, creatinine, uric acid, vitamin D, vitamin B12, blood glucose (fasting), creatinine, Serum cholesterol, serum triglyceride, HDL cholesterol, LDL cholesterol, VLDL cholesterol, total cholesterol/HDL ratio, LDL/HDL ratio, Apo Lipo A1, Apo Lipo B, Haemoglobin, PCV, MCHC, WBC, Platelets, Fasting insulin, SGOT, SGPT and calcium. Routine urine test was also conducted to assess - reaction, deposits, specific gravity and presence of albumin, sugar, ketones, phosphorus, blood, bile pigment, bile salts, urobilinogen, RBC, pus cells, epithelial cells, crystal, casts, calcium and creatinine. d. Anthropometric Measurements: Height $(123 \mathrm{~cm})$ and Weight $(7.8 \mathrm{~kg})$ were recorded at the time of admission. The ideal body weight of the patient was calculated as per ICMR standard ${ }^{6}$ and was 8.1 $\mathrm{kg}$.

e. Diet Recall: 24-hour dietary recall was taken from the mother by interview method.

The patient was diagnosed as a case of refractory epilepsy by the neurologist and the patient was put on ketogenic diet treatment.

\section{Calculation for 1200 Kcal per day diet}

The energy requirement per day is $1200 \mathrm{Kcal}$

Therefore, Macronutrient calculation is as follows considering the accepted ratio of fat and carbohydrate + protein is 2.7:1.

Fat allowance $=2.7$

Carbohydrate + Protein $=1$

Dietary Unit Quotient $(\mathrm{DUQ})=[(2.7 \times 9)+(1 \mathrm{x} 4)]=[24.3+4]=28.3($ where, $1 \mathrm{~g}$ fat $=9 \mathrm{Kcal} ; 1 \mathrm{~g}$

carbohydrate + protein $=4 \mathrm{Kcal})$

Dietary Unit Composition $($ DUC) $=$ Total calories per day/DUQ = 1200/28.3 $=42.40$

Fat allowance $(\mathrm{g})=$ DUC X number of fat units in the given ratio $=42.40 \times 2.7=114.48 \mathrm{~g} / \mathrm{day}$

Carbohydrate + Protein allowance $(\mathrm{g})=$ DUC X number of Carbohydrate + Protein units in the given ratio $=$ $42.40 \times 1=42.4 \mathrm{~g} /$ day

Protein Allowance = $20 \mathrm{~g} /$ day $(2.46 \mathrm{~g} / \mathrm{Kg}$ Ideal Body Weight/day)

Carbohydrate Allowance $=(42.4-20) \mathrm{g} / \mathrm{day}=22.4 \mathrm{~g} /$ day

Number of meal $=4$

Macronutrient allowance per meal:

Fat $=28.62 \mathrm{~g} \simeq 29 \mathrm{~g}$

Carbohydrate $=5.6 \mathrm{~g}$

Protein $=5 \mathrm{~g}$

The fat allowance per meal was derived from the combination of safflower and sea cod oil at 2.8:1 ratio.

Safflower oil = $10.5 \mathrm{~g}$, provides $7.77 \mathrm{~g}$ omega-6 (where, $100 \mathrm{~g}$ of safflower oil contains $74 \mathrm{~g}$ of omega-6)

Sea cod oil $=18.5 \mathrm{~g}$, provides $2.77 \mathrm{~g}$ omega-3 (where, $100 \mathrm{~g}$ of sea cod oil contains $15 \mathrm{~g}$ of omega-3)

Therefore, omega-6: omega-3 = 7.77:2.77 = 2.805:1 $\simeq 2.8: 1$

Intervention: After analyzing the medical investigation and EEG reports the neurologist advised PUFAKD after thorough counseling of the diet and carbohydrate wash out phase.

a. Orientation on Ketogenic Diet: Thorough training on ketogenic diet was provided to the mother and family on two consecutive days.

1. On the first day the mother was taught about carbohydrate wash out and significance of this phase to initiate nutritional ketosis.

2. On the second day she was given hands on training on ketogenic diet, type of oils, recipes, meal pattern, managing emergency situations, measuring ingredients, recording daily urine ketone level and seizure frequency in specific formats.

b. Carbohydrate wash out phase: Carbohydrate wash out phase is initiated to ensure nutritional ketosis (4+ urine ketone). During this phase the patient was given around 5 grams of carbohydrate, normal protein as per ideal body weight, in this case $12 \mathrm{~g} /$ day (as per $1.5 \mathrm{~g} / \mathrm{kg}$ IBW/day) and increased amount of fat (Safflower oil) every day. Sea cod oil has not been introduced to the patient at this phase. The oil was increased to $10 \mathrm{ml}$ per day in each meal. There was no specific amount of intake advised. During this phase the fat was allowed liberally, vegetables containing $4 \mathrm{~g}$ carbohydrate/100 $\mathrm{g}$ were allowed in prescribed manner and cereals, pulses, sugar, sweets, readymade foods, fruits and beverages were completely restricted.

c. Ketogenic diet phase: After the washout phase and successful achievement of ketosis, PUFAKD with 2.7:1 (Fat: Carbohydrate + protein) ratio was calculated and administered to maintain 4+ ketosis during the course of the treatment. In the diet regimen the ratio of omega 6 and omega 3 was 
fixed as 2.8:1 by combining safflower and sea cod oil. The fixation of ratio, daily calorie requirement and number of meals were fixed based on the patient's intake during carbohydrate wash out period, ideal body weight, age of the child and number of seizures per day. The energy was prescribed as $75 \%$ of Recommended Dietary Allowance. The urine ketone was measured with keto-diastix (Bayer's), four times a day. The urine ketone level ranges from negative to $4++$, where 0 signifies no presence of ketone bodies in the urine; Negative indicates faulty test; $1+$ to $4++$ indicate the gradual increased level of ketone bodies in the urine. 4+ and 4++ ketone levels are the indicators of higher ketosis that ensures optimum intake of fat.

Table 1: Composition of fat in PUFAKD

\begin{tabular}{|l|c|c|c|c|c|c|c|}
\hline \multicolumn{1}{|c|}{ Source } & \multicolumn{2}{|c|}{ PUFA } & \multicolumn{2}{c|}{ MUFA } & \multicolumn{3}{c|}{ SFA } \\
\hline & $\begin{array}{c}\text { Omega-3 } \\
\text { (ALA) }\end{array}$ & $\begin{array}{c}\text { Omega -6 } \\
\text { (LA) }\end{array}$ & Palmitoleic & Oleic & Palmitic & Stearic & Arachidic \\
\hline Safflower Oil & & $73.50 \%$ & & $16.7 \%$ & $7.80 \%$ & $2.10 \%$ & $0.80 \%$ \\
\hline $\begin{array}{l}\text { Sea cod Liver } \\
\text { Oil }\end{array}$ & EPA (6.6\%) & & & & & & \\
\hline
\end{tabular}

d. Meal Planning: The menu planning was based patient's intake during carbohydrate wash out phase and personal preferences, reported by the mother. Bio-engineered, ISO certified soya products were used to replace major conventional food ingredients in Indian diet like rice, pulses and wheat flour. The patient was given 15-20 recipes each month for 6 months. The number of meals was fixed as 4 per day. Variety was introduced each time to cut down monotony. The daily menu included regular Indian recipes, like egg omelet, soya khichdi, kheer, milk, vegetable cutlet, cheese cutlet, fish curry, upma etc.

e. Daily Diet: The macronutrients (carbohydrate, protein and fat) were calculated from fixed calories, ratio and number of meals by specific calculation method. The calculation was based on distributing the total calorie into macronutrients as per the ratio. The ratio was maintained at 2.7:1 for 6 months as the patient was showing promising seizure reduction with this ratio. The dietary allowance was revised each month during the follow up if required.

f. Follow up: Follow up was done every month after initiation of the diet. Clinical parameters and anthropometric measurements were assessed in every follow up. EEG and biochemical parameters were assessed every 3 months. The diet was finetuned after each follow up based on reduction in seizure frequency, ideal body weight, current body weight and urine ketone level. The outcome is tabulated below:

Table 2: Dietary allowance per day

\begin{tabular}{|l|c|c|c|c|c|c|c|}
\hline $\begin{array}{c}\text { Dietary } \\
\text { Allowance/day }\end{array}$ & $\begin{array}{c}\text { Starting } \\
\text { of KD }\end{array}$ & $\begin{array}{c}\mathbf{1}^{\text {st }} \\
\text { Month }\end{array}$ & $\begin{array}{c}\mathbf{2}^{\text {nd }} \\
\text { Month }\end{array}$ & $\begin{array}{c}\mathbf{3}^{\text {rd }} \\
\text { Month }\end{array}$ & $\begin{array}{c}\mathbf{4}^{\text {th }} \\
\text { Month }\end{array}$ & $\begin{array}{c}\mathbf{5}^{\text {th }} \\
\text { Month }\end{array}$ & $\begin{array}{c}\mathbf{6}^{\text {th }} \\
\text { Month }\end{array}$ \\
\hline Calorie (Kcal) & 1200 & 1200 & 1200 & 1200 & 1200 & 1200 & 1200 \\
\hline Protein (g) & 20 & 20 & 20 & 20 & 18 & 18 & 18 \\
\hline Fat (g) & 114.48 & 114.48 & 114.48 & 114.48 & 114.48 & 114.48 & 114.48 \\
\hline Carbohydrate (g) & 22.4 & 22.4 & 22.4 & 22.4 & 24.4 & 24.4 & 24.4 \\
\hline Ratio & $2.7: 1$ & $2.7: 1$ & $2.7: 1$ & $2.7: 1$ & $2.7: 1$ & $2.7: 1$ & $2.7: 1$ \\
\hline
\end{tabular}

Table 3: Outcome of PUFAKD Intervention

\begin{tabular}{|l|l|l|l|l|l|l|l|}
\hline $\begin{array}{c}\text { Clinical } \\
\text { Parameter }\end{array}$ & $\begin{array}{c}\text { Starting } \\
\text { of KD }\end{array}$ & $\mathbf{1}^{\text {st }}$ month & $\mathbf{2}^{\text {nd }}$ month & $\mathbf{3}^{\text {rd }}$ month & $\mathbf{4}^{\text {th }}$ month & $\mathbf{5}^{\text {th }}$ month & $\mathbf{6}^{\text {th }}$ month \\
\hline $\begin{array}{l}\text { Ideal Body } \\
\text { Weight }\end{array}$ & $8.1 \mathrm{~kg}$ & $8.2 \mathrm{~kg}$ & $8.4 \mathrm{~kg}$ & $8.5 \mathrm{~kg}$ & $8.5 \mathrm{KG}$ & $8.6 \mathrm{Kg}$ & $8.7 \mathrm{~kg}$ \\
\hline $\begin{array}{l}\text { Seizure } \\
\text { Frequency }\end{array}$ & $10-20 /$ day & $9-15 /$ day & $5-8 /$ day & $2-3 /$ day & $1-2 /$ day & NIL & NIL \\
\hline $\begin{array}{l}\text { Urine } \\
\text { Ketone }\end{array}$ & $3+$ & $3+$ & $3+$ and $4+$ & $3+$ and $4+$ & $3+$ and $4+$ & $4+$ and $4++$ & $4+$ and $4++$ \\
\hline EEG & Abnormal & Abnormal & Abnormal & Abnormal & Abnormal & Abnormal & Abnormal \\
\hline
\end{tabular}

\section{Results}

The case study demonstrated promising response of PUFAKD in terms of reducing seizure frequency.
The diet was consisting of $\mathrm{n} 3$ and n6 PUFA at 2.8:1. Taha et al (2014) has reported potential effect of the 
PUFAKD with 2.8:1 ratio in controlling uncontrolled paediatric epilepsy. ${ }^{5}$

The patient has shown $50 \%, 80 \%$ and $100 \%$ seizure reduction at $3^{\text {rd }}$ month, $4^{\text {th }}$ month and $6^{\text {th }}$ month respectively. As suggested by Winesett et al (2015) the ketogenic diet is a good alternative therapy for reducing seizure frequency in both adult and children. In this study Winesett has reported $80 \%$ seizure reduction in paediatric patients, recruited in a trial involving ketogenic diet intervention in controlling refractory seizure frequency. ${ }^{7}$

In this study, the number of AEDs has been reduced to 1 from 2 after completion of 6 months of the dietary intervention. Hamdy et al (2007) has suggested that available pharmacological treatment options for refractory epilepsy are limited in their efficacy. ${ }^{8}$ For a patient with seizures, pharmacologic treatment with available anticonvulsant medications leads to seizure control in less than $70 \%$ of patients. Surgical method can lead to control in a selective group of patients but still leaves a significant number of patients with no response. The ketogenic diet and related diets have proven to be useful in refractory childhood epilepsy.

The patient has shown $100 \%$ tolerability to the diet. As demonstrated by Ashrafi MR et al (2017), 59\% children have reported the diet as palatable and tolerable enough. ${ }^{9}$

The ideal body weight of the patient was maintained throughout the intervention. The EEG was recorded abnormal with 20\% improvement from baseline after completion of 6 months of diet therapy. There were no side effects of the PUFAKD.

\section{Discussion}

Ketogenic diet (KD) is a high-fat, low carbohydrate and normal or high protein diet. It is predominantly used in treating refractory epilepsy. Not much emphasis has been placed on the type of fat used in the diet and mostly saturated fats have been the predominant fat used according to the standard protocol. $^{4}$

Polyunsaturated fatty acids (PUFA) consist of omega-3 (n-3) and omega-6 (n-6) PUFAs. Interest in use of PUFAs started with the finding that it reduces excitability in cardiac myocytes. ${ }^{9}$ Therefore, it could be used as a therapeutic alternative for treating refractory epilepsy.

Docosahexaenoic acid (DHA) is the primary n-3 PUFA in the brain. ${ }^{5}$ PUFAKD supplies DHA to the brain. The use of PUFA in seizure reduction has been demonstrated in vitro and in vivo studies but its efficacy in humans is still not clear. ${ }^{10-12}$ Four clinical studies have shown conflicting results. ${ }^{13-16}$

The clear mode of action of n-3 and n-6 is not established separately by any human or animal study but intensive research by Yehuda (2003) has explained possible mechanism of action of PUFA in maintaining neuronal integrity. According to the review study by
Yehuda, the combination of omega- 6 and omega-3 PUFA has a critical role in modification of neuronal fluidity, modification of membrane activity bound enzymes, modification of the number and affinity of receptors, modification of the function of neuronal membrane and production of neurotransmitter and brain peptides. ${ }^{17}$

No clinical study has used PUFA as the only administered fat in the ketogenic diet.

In this context the current case study has used PUFA in its natural form, namely PUFA rich oils safflower, flaxseed and sea-cod oils in the PUFAKD. Thus PUFAKD has demonstrated promising antiepileptic action in this paediatric patient with refractory epilepsy.

\section{Conclusion}

The present case study elicits a beneficial effect of PUFAKD in refractory epilepsy patients in controlling seizures but the success of the dietary intervention is solely dependent on an efficient and trained team of neurologist, dietitian and psychologist.

\section{Acknowledgement}

The research study was not funded by any financial institute. Thanks are due to Dr. Janak Nathan, Neurologist, Sanjeev Clinic for enabling the case study.

Conflict of interest: The authors declare no conflict of interest.

\section{References}

1. Fisher R. How long for epilepsy remission in the ILAE definition? Epilepsia 2017;58(8):1486-87.

2. Patrick K., Alexis A., Anne T. Definition of drug resistant epilepsy: Consensus proposal by the ad hoc Task Force of the ILAE Commission on Therapeutic Strategies. Epilepsia 2010;51(6):1069-77.

3. Caraballo R.H, Valenzuela G.R, Armeno M. The ketogenic diet in two paediatric patients with refractory myoclonic status epilepticus. Epileptic Disorder 2015;17(4):491-95.

4. Kossoff E.H, Zupec B.A, Amark P.E. Optimal clinical management of children receiving the ketogenic diet: recommendation of the international ketogenic diet study group. Epilepsia 2008;50(2):304-17.

5. Taha A.Y, Cheon Y, Faurot K.F, et al. Dietary omega-6 fatty acid lowering increases bioavailability of omega-3 polyunsaturated fatty acids in human plasma lipid pools. Prostaglandins, Leukotrienes and Essential Fatty Acids 2014;90(5):151-57.

6. Marwaha R.K, Tandon N, Ganie M.A, et al. Nationwide reference data for height, weight and body mass index of Indian schoolchildren. Natl Med J India 2011;24(5):26977.

7. Winesett S.P, Bessone S.K, Kossoff E.H. The ketogenic diet in pharmacoresistant childhood epilepsy. Expert Review of Neurotherapeutics 2015;15(6):621-28.

8. Hamdy R.F, Turner Z, Pyzik P.L, et al. Lack of influence of body mass index on the efficacy of the ketogenic diet. J Child Neurol 2007;22(10):1167-71.

9. Ashrafi M.R, Hosseini S.A, Zamani G.R, et al. The efficacy of the ketogenic diet in infants and young 
children with refractory epilepsies using a formula-based powder. Acta Neurologica Belgica 2017;117(1):175-82.

10. Leaf A, Kang J.X, Xiao Y.F. Fish oil fatty acids as cardiovascular drugs. Current Vascular Pharmacol 2008;6(1):01-12.

11. Pagès N, Maurois $\mathrm{P}$, Delplanque $\mathrm{B}$, et al. Brain anticonvulsant protection of mice given chronic carbamazepine under various fatty acid and magnesium diet conditions. Prostaglandins, Leukotrienes and Essential Fatty Acids 2012;87(2-3):63-70.

12. Fuehrlein B.S, Rutenberg M.S, Silver J.N, et al. Differential metabolic effects of saturated versus polyunsaturated fats in ketogenic diets. J Clin Endocrinol Metabolism 2004;89(4): 1641-45.

13. Schlanger S, Shinitzky M, Yam D. Diet enriched with omega-3 fatty acids alleviates convulsion symptoms in epilepsy patients. Epilepsia 2002;43(1):103-4.

14. Yuen A.W, Sander J.W, Fluegel D, et al. Omega-3 fatty acid supplementation in patients with chronic epilepsy: a randomized trial. Epilepsy Behaviour 2005;7(2):253-58.

15. Bromfield E, Dworetzky B, Hurwitz S, et al. A randomized trial of polyunsaturated fatty acids for refractory epilepsy. Epilepsy Behaviour 2008;12(1):18790.

16. DeGiorgio C.M, Miller P, Meymandi S, et al. n-3 fatty acids (fish oil) for epilepsy, cardiac risk factors, and risk of SUDEP: clues from a pilot, double-blind, exploratory study. Epilepsy Behaviour 2008;13(4):681-84.

17. Yehuda $\mathrm{S}$. Omega-6/omega-3 ratio and brain-related functions. World Rev Nutrition and Dietetics 2003;92:3756. 